NBER WORKING PAPER SERIES

\title{
DECENTRALISATION IN AFRICA AND THE NATURE OF LOCAL GOVERNMENTS' COMPETITION: EVIDENCE FROM BENIN
}

\author{
Emilie Caldeira \\ Martial Foucault \\ Grégoire Rota-Graziosi \\ Working Paper 18126 \\ http://www.nber.org/papers/w18126
}

\author{
NATIONAL BUREAU OF ECONOMIC RESEARCH \\ 1050 Massachusetts Avenue \\ Cambridge, MA 02138 \\ June 2012
}

We thank the National Bureau of Economic Research (NBER), which has funded this project since 2009. We are grateful to the members of the Municipal Development Partnership (MDP) in Cotonou, especially Hervé Agossou, for their warm welcome, their valuable help in collecting data, their fruitful comments, and their discussions. We thank Elias Potek (University of Montreal, Geography Dept.) for his outstanding work in creating geographical maps in record time. We thank Simon Johnson (MIT), who has acted not only as a scientific mentor throughout our researching endeavors, but also as a valuable advisor. We thank Odd-Helge Fjeldstad (International Centre for Tax and Development) and François Vaillancourt (University of Montreal) for all of their helpful suggestions. We are grateful to Leonard Wantchekon (Princeton University) and the participants at the IREEP (Institut de Recherche Empirique en Economie Politique) conference, the CERDI (Centre d'Etudes et de Recherche sur le Développement International) seminar, and the CIRANO (Centre Interuniversitaire de Recherche en Analyse des Organisations) workshop, where a preliminary draft of this paper was presented in November 2010. Finally, we acknowledge financial support from the NBER Program on African Successes, especially Elisa Pepe for her amazing support throughout this project. Any remaining errors are ours. The views expressed herein are those of the authors and do not necessarily reflect the views of the National Bureau of Economic Research. s s s

NBER working papers are circulated for discussion and comment purposes. They have not been peerreviewed or been subject to the review by the NBER Board of Directors that accompanies official NBER publications.

(C) 2012 by Emilie Caldeira, Martial Foucault, and Grégoire Rota-Graziosi. All rights reserved. Short sections of text, not to exceed two paragraphs, may be quoted without explicit permission provided that full credit, including (C) notice, is given to the source. 
Decentralisation in Africa and the Nature of Local Governments' Competition: Evidence from

Benin

Emilie Caldeira, Martial Foucault, and Grégoire Rota-Graziosi

NBER Working Paper No. 18126

June 2012

JEL No. D72,H2,H7

\begin{abstract}
Decentralization has been put forward as a powerful tool to reduce poverty and improve governance in Africa. The aim of this paper is to study the existence, and identify the nature, of spillovers resulting from local expenditure policies. These spillovers impact the efficiency of decentralization. We develop a two-jurisdiction model of public expenditure, which differs from existing literature by capturing the extreme poverty of some local governments in developing countries through a generalized notion of the Nash equilibrium, namely, the constrained Nash equilibrium. We show how and under which conditions spillovers among jurisdictions induce strategic behaviours from local officials. By estimating a spatial lag model for a panel data analysis of the 77 communes in Benin from 2002 to 2008, our empirical analysis establishes the existence of the strategic complementarity of jurisdictions' public spending. Thus, any increase in the local public provision in one jurisdiction should induce a similar variation among the neighbouring jurisdictions. This result raises the issue of coordination among local governments, and more broadly, it questions the effeciency of decentralisation in developing countries in line with Oates' theorem.
\end{abstract}

Emilie Caldeira

CERDI-CNRS, Auvergne University

65 bd François Mitterrand

63000 Clermont-Ferrand

France

emiliecaldeira@gmail.com

Martial Foucault

Political Science Department

University of Montreal

CP 6128, succ. Centre-ville

Montréal, QC, H3C3J7

Canada

martial.foucault@umontreal.ca
Grégoire Rota-Graziosi

Fiscal Affairs Department

International Monetary Fund

700 19th Street, NW

Washington, DC 20431

and CERDI-CNRS, Auvergne University

grotagraziosi@imf.org 


\section{Introduction}

For two decades, decentralisation has been implemented by a large number of developing countries, especially in Africa. The World Bank in particular views this devolution as one of the major economic reforms on its agenda. In response to the failure of central states to lead the countries' development, or to limit the risk of civil conflicts in ethnically fragmented nations, decentralisation is perceived as a way to ensure political stability, to improve accountability and responsiveness of local leaders, to increase the efficiency of public policies, and ultimately, to reduce poverty.

Two main (and nonexclusive) arguments might explain this infatuation with decentralisation in developing countries. The first one is what we can call the "proximity principle": decentralisation moves local public decision makers closer to citizens. By doing this, decentralisation improves preference matching by providing greater diversity in public services to a heterogeneous population (Oates, 1972). Moreover, by reducing informational asymmetries between those in power and those governed, decentralisation should induce a higher degree of accountability in governments and greater efficiency in public spending. The second principle dates at least from the time of Tiebout's research (1956), and may be called the "competition principle." Indeed, decentralisation is supposed to induce some interjurisdictional competition among political powers: "voting with feet" and yardstick competition (Salmon, 1987) may be other ways to increase the efficiency of public spending.

However, the literature on decentralisation in developing countries essentially focuses on the proximity principle. Bardhan (2002) finds that "the institutional context" (and therefore the structure of incentives and organisation) in both developing and transition economies is quite different from those of advanced industrial economies. This author recommends going "beyond the traditional fiscal federalism literature," which is essentially associated with the competition principle. To some extent, most developing countries would not meet implicit or explicit assumptions posed by the first-generation theory of fiscal federalism. ${ }^{1}$ The Tiebout model could not be applied to developing countries where the population mobility appears to be strongly limited. Then, the existence of a yardstick competition is at least debatable

\footnotetext{
${ }^{1}$ See Oates (2005) and Vo (2010) for comprehensive surveys of this literature specifying the first and secondgeneration theories of fiscal federalism.
} 
in the context of young democracies. Finally, apart from the corruption issue emphasized by Prud'homme (1995) or Bardhan and Mookherjee (2005), developing countries face some administrative capacity constraints that the rich countries do not suffer.

These pitfalls have induced the literature on decentralisation in developing countries to focus on the effectiveness of the first argument, the proximity principle. For instance, Faguet (2004) shows that decentralisation in Bolivia has improved the responsiveness of public investment to local needs. Alderman (2002) establishes that Albanian local officials manage antipoverty programs more accurately and cost effectively than a central government agency since they are better informed. Bardhan and Mookherjee (2005) and Galasso and Ravallion (2005) have also highlighted that decentralisation improves antipoverty policies, in particular, through better intraregional targeting. These analyses suggest that decentralization may lead to poverty reduction through a bottom-up process. However, none of these authors consider the other side of decentralisation, the competition principle, which stresses the jurisdictions' interactions.

The aim of this paper is to study the relevance of the competition principle in a developing economy. This principle relies on the existence of local public goods spillovers, which are well documented in developed countries. Kelejian and Prucha (1998), Sole-Olle (2006), Redoano (2007) or Foucault, Madies, and Paty (2008) estimate expenditure reaction functions and provide empirical evidence on expenditure spillovers among (local) governments in the US, EU, Spain, and France, respectively. In the context of decentralisation, an important distinction between developing and developed countries concerns the limited administrative capacities which the rich countries do not face. This constraint may be sufficient in explaining the absence of any strategic behaviour among local governments in poor countries and to justify the current dominant approach of decentralisation in developing economies.

To deal with the extreme poverty of some developing countries' local governments, and their very limited administrative capacities, we develop a theoretical framework where two jurisdictions determine their level of public good in the presence of spillovers. We consider a generalized version of Nash equilibrium, that is, constrained Nash Equilibrium, which distinguishes our framework from preceding studies in fiscal federalism. We establish the conditions under which interactions among local governments emerge. Our empirical strategy consists of estimating expenditure reaction functions and looking for interactions between geographically 
or ethnically closes jurisdictions. It relies on a spatial lag model for a panel data set of the 77 communes of Benin (2002-2008), a representative African country. We unambiguously establish the existence of local expenditure interactions, contingent on a sufficient level of local fiscal resources. Moreover, we tackle the theoretical vagueness inherent to the nature of interjurisdictional competition: local public spending figures are strategic complements. Interactions exist not only between neighbouring communes, but also among those that are similar in terms of ethnic composition.

Our analysis contributes to a more comprehensive view of decentralisation in developing countries. It is in line with some previous work, such as that of Akin, Hutchinson, and Strumpf (2005) or Arze, Martinez-Vasquez, and Puwanti (2008) who consider local governments' interactions: the former analyzes decentralised health care in Uganda, and the latter investigates local public spending in Indonesia. ${ }^{2}$ Decentralisation induces strategic behaviours even in an African country like Benin. Moreover, the nature of these interactions, that is strategic complementarity, raises the issue of coordination between local governments. The level of spillovers is a condition that is critical to the efficiency of decentralisation, as Oates (1972) highlights. Finally, the interjurisdictional interactions that we highlight may involve some kind of competition among local governments. The competition principle and the proximity principle are both at work in developing countries. Their final effect in terms of the populations' welfare remains, however, to appreciate.

The remainder of the paper is divided into four sections. Section 2 develops a theoretical analysis of local public spending interactions, taking into account the resource constraints of some local governments. In Section 3, after a brief overview of Benin, we test the existence of interactions among Beninese local governments between 2002 and 2008. Section 4 discusses the main results by exploring the relevance of two mechanisms of the competition principle: voting with feet and yardstick competition. Section 5 concludes and raises some future challenges to appreciate the decentralisation's efficiency in the presence of the strategic complementarity of local officials' behaviour.

\footnotetext{
${ }^{2}$ Chavis (2009) studies the effect of competition on decentralization efficiency in Indonesia. The author considers the extent to which the cost per square meter of road project decreases in the number of villages that compete to obtain grants from the central government. The appreciation of competition is limited to the number of competitors. There is no analysis of interactions.
} 


\section{Theoretical background}

In this section, we present a simple theoretical model to capture the behavioral logic of local governments in determining the levels of public spending in a developing country. We take into account some constraints on these strategic behaviours that result from the extreme poverty of some local governments. Indeed, during 2002-2008, the poorest communes in Benin-Bassila, Cobly, Kandi, and Kari-Mama-respectively display average levels of per capita annual resources of $168,526,734$, and 861 CFAF (respectively equivalent to $\$ 0.31, \$ 0.97, \$ 1.35$, and \$1.58). Finally, beyond its realism, the proposed framework is built in such a way as to fit with our empirical tools and their underlying assumptions, in particular those of spatial econometrics.

\subsection{The model}

We consider two jurisdictions $(i$ and $j$ ) of the same level. We do not study political issues and then adopt a normative approach. The utility function of a representative individual in jurisdiction $i$ is given by $W^{i}\left(x_{i}, g_{i}, \theta_{i j} g_{j}\right)$, where $x_{i}$ is the private consumption, $g_{i}$ the public spending in jurisdiction $i$, and $\theta_{i j}$ is an exogenous non negative parameter, which represents the degree of spillover effect for inhabitants in jurisdiction $i$ from the public goods provided in jurisdiction $j$. We consider situations where spillovers are not symmetric $\left(\theta_{i j} \neq \theta_{j i}\right){ }^{3}$ We define $\theta=\left(\theta_{i j}, \theta_{j i}\right)$.

Since spatial empirics use weighting matrices for the strategic variables $\left(g_{i j}\right)$, the unique consistent aggregation technology of local public goods is the weighted summation. Thus, it follows:

$$
W^{i}\left(x_{i}, g_{i}, \theta_{i j} g_{j}\right)=V^{i}\left(x_{i}, g_{i}+\theta_{i j} g_{j}\right)
$$

where the weight is the parameter $\theta_{i j}$.

Our analysis focuses exclusively on current local public spending, since it is better controlled by local governments than investment expenditures. Indeed the latter are often ordered and financed by the central government. Current spending is a mix of public and merit goods. We are not able to say whether local public spending is a complement or a substitute for

\footnotetext{
${ }^{3}$ This assumption is linked to our empirical work, as well. Since proximity matrices are normalized, their sum is equal to unity for each $i$. Thus, we have $\theta_{i j}=\theta_{j i}$ if, and only if, jurisdictions $i$ and $j$ have the same number of neighbors for a proximity matrix based on contiguity.
} 
private consumption. Thus, without loss of generality concerning our analysis of jurisdictions' interactions, we consider a quasi-linear utility function where both local public spending and private consumption are Edgeworth-independent:

$$
V^{i}\left(x_{i}, g_{i}+\theta_{i j} g_{j}\right)=x_{i}+v\left(g_{i}+\theta_{i j} g_{j}\right)
$$

where the function $v($.$) is the appreciation of local public goods in jurisdiction i$ (assumed to be identical accros jurisdictions). This function is increasing in its argument $v^{\prime}()>$.0 . The sign of its second derivative, however, remains indeterminate. Indeed the concavity of function $v($.$) ,$ which is often assumed in the literature, would restrict our theoretical analysis of jurisdictional interactions to a case of strategic substitutes.

We ignore the issue of local debt, which is the focus of an important literature on soft budget constraints. Very few countries in Africa allow their local governments to run into debt. Thus, private consumption is equal to net income, and the local government faces the following hard budget constraint:

$$
R_{i}=x_{i}+c\left(g_{i}\right)
$$

where $R_{i}$ is the income of jurisdiction $i$ and $c($.$) is the cost of providing an amount g_{i}$ of local public goods. This cost is assumed to be increasing and convex: $\frac{d c\left(g_{i}\right)}{d g_{i}}>0$ and $\frac{d^{2} c\left(g_{i}\right)}{d g_{i}^{2}}>0$. This convexity reflects the increasing marginal cost of public funds. Since we focus on current spending and not on public investments, we ignore scale economies. This assumption is not rejected by a preliminary empirical test on our data. ${ }^{4}$ In order to have some interior solutions when the jurisdiction is not constrained by its wealth, we assume that

$$
\forall i, j, \quad c^{\prime \prime}\left(g_{i}\right)>v^{\prime \prime}\left(g_{i}+\theta_{i j} g_{j}\right)
$$

The convexity of the cost function of public spending must be superior to the variation of the marginal utility of public goods. This condition obviously holds if the function $v($.$) is concave.$

Substituting the expression of the private consumption given by (1) into the initial welfare

\footnotetext{
${ }^{4}$ We show the absence of scale economies in providing current public spending according to the jurisdiction's size (measured by the population density, dens). Both signs of first and second derivatives are positive and significantly different from zero: $g_{i}=3.751^{* *}$. dens $_{i}+0.001^{* * *}$. dens $_{i}^{2}$. Detailed results are provided in Table 1 in the appendix.
} 
function, we obtain the following objective function, denoted by $U^{i}$, which only depends on the strategic variables $\left(g_{i}, g_{j}\right)$ :

$$
U^{i}\left(g_{i}, \theta_{i j} g_{j}\right)=R_{i}-c\left(g_{i}\right)+v\left(g_{i}+\theta_{i j} g_{j}\right)
$$

Each local government chooses its level of public spending, considering the level of public goods in the other jurisdiction to be given. The played game is static and the Nash equilibrium may be constrained. Indeed, we take into account situations where a local government is too poor to finance the minimum of public spending. For instance, in 2007, some Beninese communes like Lalo, So-Ava, and Materi, had total budgets respectively equal to $\$ 15,432 ; \$ 31,148$; and $\$ 32,955$, which correspond to total per capita revenues of $\$ 0.17, \$ 0.35$, and $\$ 0.33$. During the same period, Cotonou had a municipal budget about 1,000 times higher ( $\$ 19$ millions or $\$ 26$ per capita) than the poorest communes. These financial gaps incite us to generalize the notion of Nash equilibrium by considering a constrained Nash equilibrium denoted by $g_{i}^{*}(\theta)$,

$$
g_{i}^{*}(\theta)=\min \left\{\bar{g}_{i}, \widetilde{g}_{i}(\theta)\right\}
$$

where $\bar{g}_{i}$ is given by the budget constraint: $R_{i}-c\left(\bar{g}_{i}\right)=0$; and $\widetilde{g}_{i}(\theta)$ is the solution of the unconstrained Nash equilibrium:

$$
\left\{\begin{array}{l}
\widetilde{g}_{i}(\theta) \equiv \underset{g_{i} \geqslant 0}{\arg \max } U^{i}\left(g_{i}, \theta_{i j} g_{j}^{*}\right) \\
\widetilde{g}_{j}(\theta) \equiv \underset{g_{j} \geqslant 0}{\arg \max } U^{j}\left(g_{j}, \theta_{i j} g_{i}^{*}\right)
\end{array}\right.
$$

The set of strategies for each jurisdiction $i$ is compact and corresponds to $\left[0, \bar{g}_{i}\right]$. The First Order Condition (FOC) of the preceding program for commune $i$ is

$$
-\frac{d c\left(g_{i}\right)}{d g_{i}}+v^{\prime}\left(g_{i}+\theta_{i j} g_{j}^{*}(\theta)\right)=0 .
$$

The Second Order Condition (SOC) is respected under condition (2).

We focus on the nature of competition among jurisdictions when it exists. These strategic interactions are captured through the sign of $\frac{d g_{i}}{d g_{j}}$. Following Bulow, Geanakoplos, and Klemperer (1985), we define local public goods as strategic complements (resp. substitutes) if, and only 
if, the marginal utility of public good in jurisdiction $i$ is increasing (resp. decreasing) in the level of local public goods in the other jurisdictions, more formally, if $\frac{\partial^{2} U^{i}\left(g_{i}, \theta_{i j} g_{j}\right)}{\partial g_{i} \partial g_{j}}>0$ (resp. $<0)$. If jurisdiction $i$ is constrained by its wealth, that is, if $c\left(\widetilde{g}_{i}(\theta)\right)>R_{i}$, we have $g_{i}^{*}=\bar{g}_{i}$ and $\frac{\partial g_{i}}{\partial g_{j}}=0$; otherwise $g_{i}^{*}=\widetilde{g}_{i}(\theta)$, and the application of the envelope theorem to (3) yields:

$$
\frac{\partial g_{i}}{\partial g_{j}}=-\frac{\frac{\partial^{2} U^{i}\left(g_{i}, \theta_{i j} g_{j}\right)}{\partial g_{i} \partial g_{j}}}{\frac{\partial^{2} U^{i}\left(g_{i}, \theta_{i j} g_{j}\right)}{\partial g_{i}^{2}}}
$$

Since the denominator corresponds to the SOC of the maximization program, the sign of $\frac{\partial g_{i}}{\partial g_{j}}$ is then equivalent to the sign of $\frac{\partial^{2} U^{i}\left(g_{i}, \theta_{i j} g_{j}\right)}{\partial g_{i} \partial g_{j}}$, which also corresponds to the sign of $v^{\prime \prime}(.) .^{5}$

\subsection{Comparative statics}

We will now consider a unilateral change in the degree of the spillovers experienced in jurisdiction $i$ from jurisdiction $j$. In so doing, we can compare the impact of an increase of public spending by a neighbouring jurisdiction, and the same variation of a more distant jurisdiction, on the level of public spending in jurisdiction i. In other words, we estimate the consequences of geographic or ethnic proximity on local governments' public spending.

For comparative statics analysis, we follow Caputo (1996). Indeed, unlike single-agent models, knowledge of how a parameter affects the marginal value of the $i$ th player's decision variables in a static game is not sufficient to determine the Nash equilibrium's comparative statics for the level of the $i$ th player's decision variables. We also must determine how the parameter's change affects the other player's best reply, and finally, how these last variations impact the marginal value of the $i$ th player's decision variable.

Considering the unconstrained Nash equilibrium $\left(\forall i, g_{i}^{*}(\theta)=\widetilde{g}_{i}(\theta)\right)$ the differentiation of (3) with respect to $\theta_{i j}$ for both jurisdictions yields:

$$
\left(\begin{array}{cc}
U_{11}^{i}(.) & \theta_{i j} v^{\prime \prime}(.) \\
\theta_{j i} v^{\prime \prime}(.) & U_{11}^{j}(.)
\end{array}\right)\left(\begin{array}{c}
\frac{\partial \widetilde{g}_{i}(\theta)}{\partial \theta_{i j}} \\
\frac{\partial \widetilde{g}_{j}(\theta)}{\partial \theta_{i j}}
\end{array}\right)=\left(\begin{array}{c}
-\theta_{i j} \widetilde{g}_{j}(\theta) v^{\prime \prime}(.) \\
0
\end{array}\right) .
$$

\footnotetext{
${ }^{5}$ If this last expression is positive, then the game played by each jurisdiction is supermodular and at least one equilibrium exists.
} 
Applying the Cramer rule we then obtain:

$$
\begin{aligned}
\frac{\partial \widetilde{g}_{i}(\theta)}{\partial \theta_{i j}} & =-\frac{\theta_{i j} \widetilde{g}_{j}(\theta)}{|J|} v^{\prime \prime}\left(\widetilde{g}_{i}(\theta)+\theta_{i j} \widetilde{g}_{j}(\theta)\right) U_{11}^{j}\left(\widetilde{g}_{j}(\theta), \theta_{j i} \widetilde{g}_{i}(\theta)\right), \\
\frac{\partial \widetilde{g}_{j}(\theta)}{\partial \theta_{i j}} & =\frac{\theta_{i j} \theta_{j i} \widetilde{g}_{j}(\theta)}{|J|} v^{\prime \prime}\left(\widetilde{g}_{i}(\theta)+\theta_{i j} \widetilde{g}_{j}(\theta)\right) v^{\prime \prime}\left(\widetilde{g}_{j}(\theta)+\theta_{j i} \widetilde{g}_{i}(\theta)\right) .
\end{aligned}
$$

where $J$ is the Jacoby matrix and its determinant is given by

$$
|J|=\left|\begin{array}{cc}
U_{11}^{i}\left(\widetilde{g}_{i}(\theta), \theta_{i j} \widetilde{g}_{j}(\theta)\right) & \theta_{i j} v^{\prime \prime}\left(\widetilde{g}_{i}(\theta)+\theta_{i j} \widetilde{g}_{j}(\theta)\right) \\
\theta_{j i} v^{\prime \prime}\left(\widetilde{g}_{j}(\theta)+\theta_{j i} \widetilde{g}_{i}(\theta)\right) & U_{11}^{j}\left(\widetilde{g}_{j}(\theta), \theta_{j i} \widetilde{g}_{i}(\theta)\right)
\end{array}\right|
$$

Generally, the sign of $|J|$ remains indeterminate since it does not rely on the sign of the Hessian matrix of a single optimisation problem, as Caputo (1996) asserts. Thus, without additional assumptions about the stability or uniqueness of the Nash equilibrium, for instance, we cannot sign $|J|$. We then obtain the following Proposition:

Proposition 1 Under our assumptions, we have:

(i) If the jurisdiction $i$ is constrained by its wealth $\left(c\left(\widetilde{g}_{i}(\theta)\right)>R_{i}\right)$, a change in $\theta_{i j}$ has no effect on the level of provided public goods in both jurisdictions;

(ii) If the jurisdiction $j$ is constrained by its wealth, a change in $\theta_{i j}$ has no effect on the level of provided public goods in jurisdiction $j$ but increases (decreases) the level of public goods in jurisdiction $i$ if public goods are strategic complements (substitutes); and

(iii) If no jurisdiction is constrained, an increase in the degree of spillover from jurisdiction $j$ to $i\left(\theta_{i j}\right)$ involves a variation in the same (opposite) sense in both jurisdictions if local public goods are strategic complements (substitutes).

Proof. $(i)$ If $g_{i}^{*}(\theta)=\bar{g}_{i}$, it is then obvious that $\frac{\partial g_{i}^{*}(\theta)}{\partial \theta_{i j}}=0$ and $\frac{\partial g_{j}^{*}(\theta)}{\partial \theta_{i j}}=0$ from differentiation of (3) with respect to $\theta_{i j}$.

(ii) If $g_{j}^{*}(\theta)=\bar{g}_{j}$ and $g_{i}^{*}(\theta)=\widetilde{g}_{i}(\theta)$, then we have $\frac{\partial g_{j}^{*}(\theta)}{\partial \theta_{i j}}=0$, which yields

$$
\frac{\partial g_{i}^{*}(\theta)}{\partial \theta_{i j}}=-\frac{\theta_{i j} \bar{g}_{j} v^{\prime \prime}\left(g_{i}+\theta_{i j} \bar{g}_{j}\right)}{\frac{\partial^{2} U^{i}\left(g_{i}, \theta_{i j} g_{j}\right)}{\partial g_{i}^{2}}},
$$

which is positive if the function $v($.$) is convex, or equivalently if local public goods are strategic$ complements given (4).

(iii) If $g_{i}^{*}(\theta)=\widetilde{g}_{i}(\theta)$ and $g_{j}^{*}(\theta)=\widetilde{g}_{j}(\theta)$, we obtain from $(5)$

$\frac{\partial \widetilde{g}_{i}(\theta)}{\partial \theta_{i j}} \frac{\partial \widetilde{g}_{j}(\theta)}{\partial \theta_{i j}}=-\theta_{j i}\left(\frac{\theta_{i j} \widetilde{g}_{j}(\theta) v^{\prime \prime}\left(\widetilde{g}_{i}(\theta)+\theta_{i j} \widetilde{g}_{j}(\theta)\right)}{|J|}\right)^{2} v^{\prime \prime}\left(\widetilde{g}_{j}(\theta)+\theta_{j i} \widetilde{g}_{i}(\theta)\right) U_{11}^{j}\left(\widetilde{g}_{j}(\theta), \theta_{j i} \widetilde{g}_{i}(\theta)\right)$. 
The parameter $\theta_{i j}$ represents the degree of 'proximity' that jurisdiction $i$ experiences from the local public goods provided by jurisdiction $j$. This proximity will be expressed in geographic or ethnic terms in our empirical analysis. An increase in $\theta_{i j}$ may represent, for instance, the reduction of the transportation costs to move across communes $i$ and $j$, or a stronger similarity in their ethnic compositions. Such variations would induce two effects on $g_{i}$, a direct effect, and an indirect (strategic) one, through the level of public goods provided by the neighbour $\left(g_{j}\right)$. If jurisdiction $i$ is constrained by its wealth, any change in $\theta_{i j}$ does not affect the equilibrium value. Indeed, as the level of public spending in this jurisdiction is a corner solution, neither the direct effect nor the strategic effect would come into play. If the other jurisdiction, namely $j$, is constrained, then only the direct effect of $\theta_{i j}$ would influence $g_{i}$. An increase of $\theta_{i j}$ induces an increase (decrease) in $g_{i}$ when local public expenditures are strategic complements (substitutes). Finally, if no jurisdiction is constrained, then both effects are at play. Without additional assumptions, however, particularly on the sign of $|J|$, we can only conclude that an increase in $\theta_{i j}$ would induce increases or decreases in levels of local public goods in both jurisdictions in the presence of strategic complements. Otherwise, in the presence of strategic substitutes, an exogenous change of $\theta_{i j}$ would involve opposite variations among jurisdictions.

Following Dixit (1986) or Kolstad and Mathiesen (1987), we assume the uniqueness and the stability of the Nash equilibrium through the following assumption: ${ }^{6}$

$$
|J|>0
$$

This relation enables us to pinpoint the types of variations resulting from the two aforementioned kinds of parameter changes. We obtain the following Proposition:

Proposition 2 Under our assumptions and (7), we find the following:

(i) An increase in the degree of spillover from jurisdiction $j$ to $i\left(\theta_{i j}\right)$ entails an increase in the level of public goods in both jurisdictions if local public goods are strategic complements, and (ii) an increase in the degree of spillover from jurisdiction $j$ to $i\left(\theta_{i j}\right)$ entails a decrease in the level of public goods in jurisdiction $i$, and an increase in the level of public goods in jurisdiction $j$ if local public goods are strategic substitutes.

\footnotetext{
${ }^{6}$ If we adopt the contraction approach (see Vives, 1999), the condition of equilibrium uniqueness involves

$$
U_{11}^{i}\left(g_{i}, \theta_{i j} g_{j}\right)+\left|v_{12}^{i}\left(g_{i}, \theta_{i j} g_{j}\right)\right|<0
$$

which yields that $|J|$ is positive.
} 
Proof. Immediate from (5).

Assuming the uniqueness of the Nash equilibrium allows us to specify the type of deviation from public spending when the degree of spillovers varies. To sum up our theoretical results, we show that spillovers among jurisdictions may involve strategic behaviours, which in turn lead to a competition process. However, the presence of local public goods spillover is not a sufficient condition of strategic behaviours among communes. Without restricting the nature of such a competition, we estimate to what extent the level of provided public good is affected by a deviation in the degree of spillover. ${ }^{7}$

Our theoretical framework yields the following implications:

1. The provision of local public goods with spillovers may induce two cases:

(a) Strategic interactions in terms of complements or substitutes (classical result);

(b) The lack of strategic interactions due to the insufficient level of fiscal resources, despite positive externalities (largely ignored by the relevant literature);

2. Under the presence of strategic complements, the expected quantity of public goods in jurisdiction $i$ will positively depend on the level of public goods allocated by jurisdiction $j$; In the presence of strategic substitutes, an opposite relationship is expected.

\section{Empirical evidence of public spending interactions in a less developed country: The case of Benin}

Our empirical analysis focuses on Benin, a young democracy. After a brief overview of this country's history, we test the existence of strategic interactions among local governments' spending by estimating a spatial dynamic econometric model.

\subsection{Benin overview}

With a per capita income of $\$ 570$ in 2007 , and a ranking of 163 out of 177 countries, ${ }^{8}$ Benin remains one of the poorest nations in the world. As with many African countries, Benin is

\footnotetext{
${ }^{7}$ Proposition 2 (ii) is similar to Proposition 8 in Bloch and Zenginobuz (2007), who consider only the case of strategic substitutes.

${ }^{8}$ Human Development Report (2007).
} 
ethnically fragmented with about 42 recorded ethnicities (see Figure 2). ${ }^{9}$ Since its independence on August 1, 1960, the history of Benin has been chaotic. A succession of military governments ended in 1972, with the last military coup being led by Mathieu Kerekou, who established a government based on Marxist-Leninist principles. A move to democracy began in 1989 . Two years later, free elections ushered in former Prime Minister Nicephore Soglo (a former World Bank official) as President. Kerekou regained power in 1996, during elections fraught with irregularities, and won the subsequent election in 2001. Having served two terms and being over 70, he was ineligible to run in the presidential elections of 2006 . He was succeeded by Thomas Boni Yayi, an independent political outsider who had previously headed the West African Development Bank. In March 2007, President Yayi Boni strengthened his position after the legislative elections, where his coalition, Force Cauris pour un Benin Emergent (FCBE), won the largest number of seats (35 out of 83), and negotiated a progovernment majoritarian coalition in Parliament with seven minor parties.

This democratic evolution was accompanied by a huge transformation of the political and administrative organisation. Since 1998, Benin has undergone a decentralisation process that became effective with the first local elections in 2002-2003. The second local elections took place in 2008. ${ }^{10}$ As depicted in Figure 1, Benin is divided into twelve départements which, after decentralisation, were subdivided into 77 communes, themselves divided into 546 districts. Départements are managed by a representative of the central government. In contrast, communes are governed by a directly elected local government. The average size of commune, presented in the following map, reaches about 90,000 inhabitants.

\section{Insert Map 1}

In January 1999, Law 97-029 shifted the transferred competencies from the central government to the 77 communes. Theoretically, competencies of Beninese communes range from elementary school to economic development, and include the transport infrastructure, environment (hygiene), health and social goods, tourism, security and marketplace management. As

\footnotetext{
${ }^{9}$ Among the 42 ethnic groups, the most prominent are the Fon and the Adjas in the south, the Baribas and the Sombas in the north, and the Yorubas in the southeast. As Figure 2 displays, the north is less fragmented and less urbanized than the south.

10 The first round of municipal elections was held on December 15, 2002 and the second round took place on January 19, 2003, with an average rate of turnout estimated at 70 percent.
} 
in most of African countries, however, an adequate transfer of resources did not accompany this competencies transfer. Beninese communes are characterised by very low levels of resources (only about 4.5 percent of country tax revenues, or equivalently 0.7 percent of GDP). ${ }^{11}$ Moreover, important inequalities appear between communes: the resources of the ten poorest communes represent 5 percent of the five richest ones (see Figure 3 for the DHS score by commune).

\section{Insert Maps 2 and 3}

\subsection{Econometric framework}

Horizontal interactions entail a fiscal reaction function that depicts how the decision variable for a given jurisdiction depends on the decisions of other jurisdictions. To test the existence and the strength of such functions, we test spatial dependence in a panel data framework. Following the relevant empirical literature, we consider a specification, in the most general form, in which commune $i$ public expenditure in year $t$, defined by $G_{i t}$, is a function of its neighbours' same public choice, $G_{j t}$. It gives the following specification:

$$
G_{i t}=\sum_{i j} \rho_{i j} \cdot G_{j t}+\beta \cdot X_{i t}+\alpha_{i}+\varepsilon_{i t}
$$

where $i=1, \ldots, n$ denotes a commune and $t=1, \ldots, T$ a time period; $\alpha, \beta$, and $\rho$ are unknown parameters; and $\varepsilon_{i t}$ a random error. We allow $G_{i t}$ to depend on a vector of specific controls $X_{i t}$ and we include a commune-specific effect, $\alpha_{i}$. In this way, we correct for all time-invariant communes' characteristics, observed or unobserved.

Since there are too many parameters $\rho_{i j}$ to be estimated, the usual procedure is to consider:

$$
G_{i t}=\rho \cdot A_{j t}+\beta \cdot X_{i t}+\alpha_{i}+\varepsilon_{i t}
$$

where $A_{j t}=\sum \theta_{i j} \cdot G_{i t}$ is the weighted average vector of public spending in the set of the other

\footnotetext{
${ }^{11}$ Local resources are mainly communes' own resources (about 70 percent). Property taxes and licenses for exercising a trade or profession (patente) represent 90 percent of local tax revenues (see Chambas, 2010 for a detailed analysis of local fiscal resources in sub-Saharan Africa, particularly in Benin). Retroceded taxes, which come from transfers of state tax revenue to local governments, account for about 10 percent of local resources.
} 
local governments $j$ at time $t$.

We explore a variety of weighting schemes to allow different patterns of spatial interactions. First, we choose a common geographical definition of neighbouring jurisdictions based on a contiguity matrix, denoted by $\theta^{\text {neigh }}$, where the value 1 is assigned if two jurisdictions share the same border, and 0 otherwise. Second, we define an ethnic weight matrix, $\theta^{\text {ethn }}$, based on the ethnic proximity of communes' inhabitants. In so doing, we test the existence of spending interactions between communes that are similar with respect to ethnicity. Finally, we consider two benchmark weighting schemes: a uniform weight matrix $\left(\theta^{\text {uni }}\right)$ where weights are assumed to be identical for all communes $j$ and a 'placebo' weight matrix ( $\left.\theta^{\text {plac }}\right)$ where weights are random. ${ }^{12}$ The uniform scheme captures the critique of Manski (1993): the interdependence of fiscal choices may result from a "common intellectual trend" that drives fiscal choices in the same directions and not from jurisdictions' strategic behaviours. The placebo matrix, also used in Lockwood and Migali (2009), ascertains that observed interactions are not an artefact of the estimation procedure. ${ }^{13}$

In order to take into account the persistence in public expenditure, we consider a dynamic version of equation (9) and introduce the lagged dependent variable $G_{i t-1}$ as a right-hand side:

$$
G_{i t}=\lambda \cdot G_{i t-1}+\rho \cdot A_{j t}+\beta \cdot X_{i t}+\alpha_{i}+\varepsilon_{i t} .
$$

Regression (10) raises some important econometric issues as described by Brueckner (2003). First, public spending is jointly determined. Thus neighbours' decisions are endogenous and correlated with the error term $\varepsilon_{i t}$. Ordinary least squares estimation of the parameters is then inconsistent, requiring alternative estimation methods based on the instrumental variables method (IV) or on maximum likelihood (ML). Second, the omission of explanatory variables that are spatially dependent may generate spatial dependence in the error term, which is given by: $\varepsilon_{i t}=\tau \theta \varepsilon_{i t}+v_{i t}{ }^{14}$ Ignoring spatial error dependence may provide false evidence of strategic interaction. To deal with such a problem, two approaches are available: the ML estimator, which

\footnotetext{
${ }^{12}$ We generate a random number distributed between 0 and 1 for each commune. The weight assigned between two communes is the difference between its random numbers.

${ }^{13}$ Weights are normalized so that their sum equals unity for each $i$ for all weight matrices. This assumes that spatial interactions are homogeneous: each neighbor has the same impact on the commune.

${ }^{14}$ Using a data panel helps to eliminate spatial error dependence which arises through spatial autocorrelation of omitted variable, since the influence of such variables is partly captured in community-specific intercept terms.
} 
takes into account the error structure (see Case, Rosen, and Hines, 1993), or the IV method, which yields consistent estimations even with spatial error dependence. ${ }^{15}$ Previous analysis of local governments' interactions ${ }^{16}$ use the tests of Anselin, Bera, Florax, and Yoon (1996), to verify the hypothesis of error independence, since these are not contaminated by uncorrected spatial error dependence and may detect the presence of spatial lag dependence. However as Nickell (1981) mentions, the introduction of a lagged dependent variable induces the inconsistency of the previous estimators. We then use the GMM System estimator after verifying the hypothesis of error independence and estimating the static model with the ML estimator. This econometric strategy is commonly shared in the relevant literature. The GMM estimators allow us to control for both unobserved country-specific effects and the potential endogeneity of the explanatory variables. We also introduce a trend variable, $T_{t}$, to capture shocks in each period, which are common to all local governments, and other specific controls commonly used in the empirical literature. We then obtain:

$$
\begin{gathered}
G_{i t}=\quad \lambda \cdot G_{i t-1}+\rho \cdot A_{j t}+\beta_{1} \cdot D_{i t}+\beta_{2} \cdot N_{d t}+\beta_{3} \cdot O_{c t}+\beta_{4} \cdot P R_{i t} \\
+\beta_{5} \cdot E_{t-1}+\beta_{6} \cdot E_{t}+\beta_{7} \cdot E_{t+1}+\beta_{8} \cdot T_{t}+\alpha_{i}+\varepsilon_{i t}
\end{gathered}
$$

where $D_{i t}$ is the population density of jurisdiction $i$ on year $t$, which captures scale economies in public spending and may be spatially distributed. ${ }^{17}$ Due to the lack of data at the commune level for appreciating wealth variations, we consider the employment rate in department $d$ on year $t$, denoted by $N_{d t}$. It enables a partial control of common shocks that would also be spatially correlated. The variable $O_{c t}$ is a trade openness measure at country level that controls for macroeconomic shocks, since developing countries are vulnerable to foreign trade (Rodrik, 1998). ${ }^{18}$ Other control variables are introduced in regression (11): a dummy variable, denoted by $P R_{i t}$, captures some partisan effects; ${ }^{19}$ and dummies for election years, denoted by $E_{t-1}, E_{t}$

\footnotetext{
${ }^{15}$ With the IV approach, a typical procedure is to use the weighted average of neighbors' control variables as instruments (see Kelejian and Prucha, 1998). The ML method consists in using a nonlinear optimization routine to estimate the spatial coefficient $\rho$ (see Brueckner, 2003).

${ }^{16}$ For instance, Brueckner (1998), Brueckner and Saavedra (2000), Saavedra (2000) or Foucault, Madies, and Paty (2008).

${ }^{17}$ Population density is the number of inhabitants per square kilometer. Per capita expenditures and population density are in log. Per capita expenditures are corrected for inflation.

${ }^{18}$ We measure trade openness as a ratio of total foreign trade (exports plus imports) to GDP, as it is the one most often used in empirical studies.

19 The variable takes the value 1 if the local government in jurisdiction $i$ has the same partisan affiliation as the president in office. Until he stepped down in March 2006, Mathieu Kérékou enjoyed strong support in the north of the country (Alibori, Atacora, Borgou, and Donga), which was considered his fief. When Boni Yayi
} 
and $E_{t+1}$, allow one to test the opportunistic behaviour hypothesis of local policymakers. ${ }^{20}$ With respect to our theoretical results (Proposition 1), $\rho \neq 0$ involves the existence of some strategic interactions. Moreover, $\rho>0(\rho<0)$ means that an increase in the degree of spillovers involves a variation in the same (opposite) sense of local public goods levels, that is public spending is a strategic complement (substitute).

In the theoretical section, we also highlight the point that strategic interactions may be restricted by the extreme poverty of some local governments. To test this hypothesis, we define a common indicator of fiscal autonomy, denoted by $F_{i t}$, which is the ratio of jurisdictions' own resources to their total resources, and we consider the following specification:

$$
\begin{aligned}
G_{i t}=\quad & \lambda \cdot G_{i t-1}+\rho \cdot A_{j t}+\varphi \cdot A F_{i t}+\beta_{1} \cdot D_{i t}+\beta_{2} \cdot N_{d t}+\beta_{3} \cdot O_{c t} \\
+ & \beta_{4} \cdot P R_{i t}+\beta_{5} \cdot E_{t-1}+\beta_{6} \cdot E_{t}+\beta_{7} \cdot E_{t+1}+\beta_{8} \cdot T_{t}+\alpha_{i}+\varepsilon_{i t},
\end{aligned}
$$

where $A F_{i t}=A_{j t} * F_{i t}$. If strategic interactions are actually contingent on each commune's fiscal autonomy, we should observe that the coefficient of $A_{j t}$ is not significant; and that the coefficient of $A F_{i t}$ is significant and positive (negative) if public spending is strategic complements (substitutes).

\subsection{Results}

Our dataset covers the 77 communes of Benin for the period 2002-2008. The communes' data for current spending come from the Beninese Ministry of Finance and Economy. The other control variables are drawn from World Development Indicators, Afrobarometers, Demographic and Health Surveys, and 77 monographs provided by the European Union.

First, we investigate whether or not jurisdictions' public spending figures are correlated, and which are the more likely sources of correlation, spatial lag or spatial error dependence. We follow Anselin, Le Gallo, and Jayet (2006), who proposed two in-depth tests, based on the Lagrange multiplier principle for panel data indicating the most likely source of spatial dependence. We first estimate (11) using OLS for both contiguity and ethnic matrix without

was elected, he affirmed his desire for political openness. His fiefs are concentrated in the south of the country, in particular, Atlantic, Collines, and Mono. Finally, about 40 percent of the departments have shared the same partisan affiliation as the president in office.

${ }^{20} E_{t-1}, E_{t}$, and $E_{t+1}$ are dummy variables that take the value 1 the year before, the year of, and the year after the election, respectively, and 0 otherwise. 
taking into account the influence of public spending in other jurisdictions $(\rho=0)$, and the lagged value of our dependent variable $(\lambda=0)$. Spatial tests results are shown in Table 2. They indicate the presence of spatial lag dependence for public spending, but not the existence of spatial error dependence for both matrices.

Second, since the hypothesis of error independence is verified, we estimate (11) using ML with specific effects for both contiguity and ethnic matrices without taking into account the lagged value of our dependent variable $(\lambda=0)$. However, we consider the influence of the expenditure set by other jurisdictions $(\rho \neq 0)$. The estimation results are presented in Table 3 . The coefficient of the weight average vector is always significant and positive.

Finally, the one step robust system GMM provides an estimation of our dynamic model (11) for all weighting schemes, taking into account the lagged value of the dependent variable $(\lambda \neq 0)$. We adopt the assumption of weak exogeneity in employment rates and trade openness while other explanatory variables are assumed to be strictly exogenous. The weighted average vector of per capita public spending of other local governments is, as noted before, suspected of being endogenous. The lagged levels of variables are used as instruments in the regressions in level as well as in the regressions in difference. We collapse instruments and limit their number since too many instruments would lead to an inaccurate estimation of the optimal weight matrix, biased standard errors, and, therefore, incorrect inference of overidentification tests (see Roodman, 2009). ${ }^{21}$ Table 4 displays estimation results.

Insert Table 4

We focus our attention on (1) (2) (3) (4) and (5), that is, the system GMM estimations for contiguity, ethnicity, uniformity, and placebo matrices. First we note: $(i)$ the orthogonality conditions are respected, ${ }^{22}$ (ii) the coefficient on the lagged dependent variable is always

\footnotetext{
${ }^{21}$ The lags of at least two earlier periods for weak exogenous variables, and three earlier periods for endogenous variables, are used as instruments. The lagged dependent variable is instrumented by lags of the dependent variable from at least two earlier periods. We use two lags for endogenous and weak exogenous variables.

22 The consistency of the estimator depends on whether or not lagged values of explanatory variables are valid instruments. The criteria for the selection of instruments are found in two specification tests (Arellano and Bond, 1991). With the Hansen test, we test the null hypothesis of the overall validity of the instruments' orthogonality conditions. The second test concerns the serial correlation of residuals. It examines the hypothesis that the residuals from the first-differentiated estimating equation are not second-order correlated. In our case, both statistics confirm the validity of the instruments used.
} 
significant and positive, confirming the consistency of the autoregressive specification, ${ }^{23}$ and (iii) after correcting for endogeneity, the coefficient of the the weighted average vector of public spending in the set of the other local governments is significant at least at a 1 percent level, and positive for ethnic and contiguity matrices.

Following Manski (1993), these preliminary results are not sufficient to conclude that strategic interactions exist. Indeed, a common trend would drive local governments' decisions in the same direction, yielding a positive sign of the interactions' coefficient, but not a specific pattern in the type of communes in interactions. The coefficient of interaction with the uniform matrix is significant, as seen in column 3. To go beyond Manski's critique, we estimate the coefficient for the contiguity matrix after checking for common trends. In column 4, we see that the neighbouring interaction coefficient remains significantly positive: local governments actually interact with each other. ${ }^{24}$ Moreover, the placebo matrix (column 5) does not show any evidence of strategic interactions. Interactions among jurisdictions that are geographically or ethnically close are not an artefact of our estimation procedure. Note that in Table 5, we also establish that there were no strategic interactions before 1998, when the decentralisation process began in Benin. ${ }^{25}$

We conclude that there are strategic interactions between neighbouring jurisdictions. Moreover, public spending are strategic complements as in most empirical studies. ${ }^{26}$ An average increase of 10 percent in the neighbouring jurisdictions' public spending induces an increase of around 6.2 percent in local expenditure. These interactions also exist between communes that are ethnically close, though they are less important (5.1 percent). ${ }^{27}$ Columns 7 and 8 provide some robustness tests of these results. We consider some alternative matrices: the $\theta^{\text {neigh } 2}$ matrix, in which the value of 1 is assigned if two communes belong to the same departeent and 0 otherwise; the $\theta^{\text {ethn } 2}$ matrix where the value of 1 is assigned if two communes have the same

\footnotetext{
${ }^{23}$ As this coefficient provides an estimate $\lambda$ varying between 0.411 and 0.629 , the result indicates some level of persistence in public expenditure.

24 The interactions' coefficient also remains significantly positive for the ethnic matrix after a similar correction.

${ }^{25}$ We run the same regressions as we did previously for the period 1994-1998. The coefficients of interaction with all matrices are not significant.

26 Note that, in their study of the Public Health Sector in Uganda, Akin, Hutchinson, and Strumpf (2005) provide evidence for the hypothesis that spillover effects cause spending on public goods in one district to reduce spending on public goods in neighboring districts. Local public spending are, in this case, strategic substitutes.

27 Since different ethnic groups are located in close geographical areas, we can assume that the geographic matrix overlies the ethnic matrix. We estimate the coefficient for the ethnic matrix after checking for geographical interactions in column 6 and it remains significant and stable.
} 
dominant ethnic group and 0 otherwise. The coefficient of the weighted average vector of the other local governments' public spending remains positive and significant at the 5 percent level for the $\theta^{\text {neigh } 2}$ matrix, and at 10 percent for the ethnic matrix $\theta^{\text {ethn } 2}$.

Columns 9 and 10 concern regression (12), allowing us to appreciate the effect of the communes' wealth constraints. As expected, the coefficient of the interaction variable between neighbours' spending decisions and the indicator of fiscal autonomy $(\varphi)$ is positive and significant. Moreover the coefficient for strategic interaction alone $(\rho)$ is no longer significant. We unambiguously conclude that strategic interactions only exist between unconstrained local governments. Finally, in considering the proposed control variables, we observe the opportunistic behavior of local jurisdictions, since dummies associated with the pre-election years indicate an increase in public spending. ${ }^{28}$ Moreover, having a local government with the same political affiliation as the president in office increases public expenditure, too. ${ }^{29}$

Our empirical work suggests that decentralisation has induced interjurisdictional strategic interactions among Beninese communes with regard to current expenditures that appear to be strategic complements. Moreover, our results confirm that such strategic interactions are contingent on communes' respective fiscal autonomy in this developing country.

\section{Discussion}

Before concluding, we return to some potential explanations for the existence of interjurisdictional spillovers, more specifically concerning two mechanisms of the competition principle, the interjursidictional migration, that is, the Tiebout hypothesis, and the electoral pressure, or yardstick competition. The existence of interjurisdictional interactions we have established leads us to reconsider these arguments.

Despite the lack of relevant data, we may mention some facts concerning interjurisdic-tional migrations in Benin. It is evident that differences in relative demographic growth of Beninese

\footnotetext{
${ }^{28}$ To understand the sign of the coefficient associated with the election year dummy, one must refer to the election calendar and budget votes. Local elections take place at the beginning of March, and the definitive budget must be adopted before March 31. Therefore, in the year before the elections, decision makers increase current expenditures and decrease them the year after, since the definitive budget is approved.

${ }^{29}$ Note that we find a positive and significant sign for the parameter associated with the employment rate, which indicates the effect of economic conjuncture. The trend variable remains, as expected, significant and negative. Indeed, per capita public expenditure has decreased by 75 percent over the period, despite little growth between 2004 and 2006.
} 
communes cannot be explained by differences in birth rate alone. For instance, Abomey-Calavi, a dynamic commune spreading over Cotonou, has an annual population growth rate of 9.44 percent, while Boukoumbe, a highly rural commune, has an annual population growth rate of 0.41 percent. Internal migrations exist in Benin and seem to be largely guided by the opportunities offered by cities. ${ }^{30}$ The migration's motives are various ${ }^{31}$ - schooling, job search or family ties - but could be connected, at least partially, to the provision of public goods at the local level, as is the case in developed countries. Moreover, these migrations occur generally between communes belonging to the same department, ${ }^{32}$ which could explain the existence of strategic interactions between geographically proximate communes.

Since our dataset covers two local elections (2003 and 2008), we are able to extend our preceding empirical analysis to test the existence of some kind of yardstick competition among Beninese communes During the electoral period, political campaigns should increase interactions among local governments, since more information is available on the fiscal policies of local decision makers, thereby inducing or reinforcing a yardstick competition effect. Hence, the empirical challenge lies in evaluating the impact of elections on strategic interactions. A straightforward way to test such an effect is to interact the neighbours' spending decisions $\left(A_{j t}\right)$ with the dummy for the election years, and estimate two different interaction coefficients, one for years of election $\left(E Y_{t}\right)$ and one for all the other periods $\left(N E Y_{t}\right) \cdot{ }^{33}$ If elections actually reinforce the exposure of jurisdictions, we should observe the coefficient of $\left(A_{j t} \times E Y_{t}\right)$ being more significant and higher than the coefficient of $\left(A_{j t} \times N E Y_{t}\right)$ as policymakers should be particularly concerned about their neighbours' decisions during election periods.

\section{Insert Table 6}

\footnotetext{
30 The analysis of the migrants' distribution (Third Census of Population and Housing, 2002) shows that the départements of Atlantique and Littoral, which are the most urbanized, welcome 41.3 percent of migrants, which is more than 4 migrants in 10.

31 Third Census of Population and Housing (2002).

32 For instance, in the department of Couffo, more than half of the migrants lived in the same department. Moves between contiguous departments are also important; more than half of the immigrants of the department of Atlantique lived in the department of Littoral.

${ }^{33}$ Formally, we test:

$$
\begin{aligned}
& G_{i t}=\lambda S_{i t-1}+\rho^{\prime} \cdot\left(A_{j t} \times E Y_{t}\right)+\rho^{\prime \prime} .\left(A_{j t} \times N E Y_{t}\right)+\beta_{1} \cdot D_{i t}+\beta_{2} \cdot N_{d t} \\
& +\beta_{3} . O_{c t}+\beta_{4} \cdot P R_{i t}+\beta_{5} \cdot E Y_{t}+\beta_{6} \cdot N E Y_{t}+\beta_{7} \cdot T+\alpha_{i}+\varepsilon_{i t},
\end{aligned}
$$

where $E Y_{t}=E_{t-1}+E_{t}$ and $N E Y_{t}=\left(1-\left(E_{t-1}+E_{t}\right)\right)$.
} 
As expected, Table 6 shows that the coefficient is slightly higher and more significant in election periods than in other periods with both matrices, indicating that expenditure decisions are slightly more dependent on neighbours during election periods. However, Wald tests do not indicate that coefficients are significantly different at the 10 percent level. Yardstick competition may have some effect, but it is not the main channel of communes' interactions.

\section{Conclusion}

The aim of our paper was to study local governments' interactions in Benin. These interactions could be very modest, given the scarcity of local public resources. We show that this is not the case. Indeed, we establish that decentralisation in Benin entails interjurisdictional interactions. These interactions are not a common trend. They exist not only among neighbouring local jurisdictions but also among communes that are close in terms of ethnic composition. We also emphasise both the influence of partisan affiliation, and the opportunistic behaviour of local governments before elections. This African democracy appears to be as concerned as developed democracies with strategic fiscal interactions.

The existence of strategic complementarity among local governments in developing countries may have some attractive consequences for the issue of decentralisation in these coun-tries. In the game theory literature, strategic complementarity is often associated with the multiplicity of Nash equilibria, then with a coordination issue. ${ }^{34}$ In the context of decentralisation in developing countries, our results mean that several equilibria may exist and some may be Pareto dominated. A theoretical indecision then remains on the final effect of decentralization on the population's welfare. This inconclusiveness may only be solved through further empirical studies. However, strategic complementarity may also induce some interesting features, particularly in the context of foreign aid. Assume, for instance, that a commune receives foreign aid, which leads to an increase local public spending. Due to strategic complementarity, such an increase will induce similar variations in public spending in neighbouring communes. A multiplier comparable to the social multiplier put forward by Glaeser, Sacerdote, and Scheinkman (2003) results from strategic complementarity and positive spillovers. This multiplier, which remains to be evaluated in Benin, and more broadly, in African countries, may reinforce the appeal of

\footnotetext{
${ }^{34}$ In contrast, strategic substitutability raises the question of the existence of a Nash equilibrium.
} 
decentralized foreign aid. 


\section{References}

Akin, J., P. Hutchinson, and K. Strumpf (2005): "Decentralisation and government provision of public goods: The public health sector in Uganda," The Journal of Development Studies, 41(8), 1417-1443.

Alderman, H. (2002): "Do local officials know something we don't? Decentralization of targeted transfers in Albania," Journal of Public Economics, 83(3), 375-404.

Anselin, L., A. K. Bera, R. Florax, and M. J. Yoon (1996): "Simple diagnostic tests for spatial dependence," Regional Science and Urban Economics, 26(1), 77-104.

Anselin, L., J. Le Gallo, and H. Jayet (2006): "Spatial econometrics and panel data models," in Handbook of panel data econometrics, ed. by L. Matyas, and P. Sevestre. Kluwer, Dordrecht.

Arellano, M., and S. Bond (1991): "Some tests of specification for panel data: Monte Carlo evidence and an application to employment equations," Review of Economic Studies, $58(2), 277-97$.

Arze, J., J. Martinez-Vasquez, and R. Puwanti (2008): "Local government fiscal competition in developing countries: The case of Indonesia," Urban Public Economics Review, (8), 13-45.

Bardhan, P. (2002): "Decentralization of governance and development," Journal of Economic Perspectives, 16(4), 185-205.

Bardhan, P., and D. MookherJee (2005): "Decentralizing antipoverty program delivery in developing countries," Journal of Public Economics, 89(4), 675-704.

Bloch, F., and U. Zenginobuz (2007): "The effect of spillovers on the provision of local public goods," Review of Economic Design, 11(3), 199-216.

Brueckner, J. K. (1998): "Testing for strategic interaction among local governments: The case of growth controls," Journal of Urban Economics, 44(3), 438-467.

- (2003): "Strategic interaction among governments: An overview of empirical studies," International Regional Science Review, 26(2), 175-188.

Brueckner, J. K., and L. A. SaAvedra (2000): "Do local governments engage in strategic property-tax competition?," Econometric Society World Congress 2000 Contributed Papers 0357, Econometric Society.

Bulow, J. I., J. D. Geanakoplos, and P. D. Klemperer (1985): "Multimarket oligopoly: Strategic substitutes and complements," Journal of Political Economy, 93(3), 488-511.

Caputo, M. R. (1996): "The envelope theorem and comparative statics of Nash Equilibria," Games and Economic Behavior, 13(2), 201-224.

Case, A. C., H. S. Rosen, and J. J. Hines (1993): "Budget spillovers and fiscal policy interdependence : Evidence from the states," Journal of Public Economics, 52(3), 285307.

Chavis, L. (2009): "Decentralizing development: Allocating public goods via competition," Journal of Development Economics, 12(4), 264-274. 
Dixit, A. K. (1986): "Comparative Statics for oligopoly," International Economic Review, $27(1), 107-22$.

FAGUet, J.-P. (2004): "Does decentralization increase government responsiveness to local needs? Evidence from Bolivia," Journal of Public Economics, 88(3-4), 867-893.

Foucault, M., T. Madies, and S. Paty (2008): "Public spending interactions and local politics. Empirical evidence from French municipalities," Public Choice, 137(1), 57-80.

Galasso, E., and M. Ravallion (2005): "Decentralized targeting of an antipoverty program," Journal of Public Economics, 89(4), 705-727.

Glaeser, E. L., B. I. Sacerdote, and J. A. Scheinkman (2003): "The social multiplier," Journal of the European Economic Association, 1(2-3), 345-353.

Kelejian, H. H., and I. R. Prucha (1998): "A generalized spatial two-stage least squares procedure for estimating a spatial autoregressive model with autoregressive disturbances," The Journal of Real Estate Finance and Economics, 17(1), 99-121.

Kolstad, C. D., and L. Mathiesen (1987): "Necessary and sufficient conditions for uniqueness of a Cournot Equilibrium," Review of Economic Studies, 54(4), 681-90.

Lockwood, B., And G. Migali (2009): "Did the single market cause competition in excise taxes? Evidence from EU countries," Economic Journal, 119(536), 406-429.

Manski, C. F. (1993): "Identification of endogenous social effects: The reflection problem," Review of Economic Studies, 60(3), 531-42.

Nickell, S. J. (1981): "Biases in dynamic models with fixed effects," Econometrica, 49(6), $1417-26$.

OAtes, W. (2005): "Toward a second-generation theory of fiscal federalism," International Tax and Public Finance, 12(4), 349-373.

OAtes, W. E. (1972): Fiscal federalism. Harcourt Brace Jovanovich, New York.

Prud'homme, R. (1995): "The dangers of decentralization," World Bank Research Observer, 10(2), 201-20.

Redoano, M. (2007): "Fiscal interactions among European countries. Does the EU matter?," CESifo Working Paper Series CESifo Working Paper No., CESifo GmbH.

Rodrik, D. (1998): "Why do more open economies have bigger governments?," Journal of Political Economy, 106(5), 997-1032.

Roodman, D. (2009): "A note on the theme of too many instruments," Oxford Bulletin of Economics and Statistics, 71(1), 135-158.

SAAVEDRA, L. A. (2000): "A model of welfare competition with evidence from AFDC," Journal of Urban Economics, 47(2), 248-279.

Salmon, P. (1987): "Decentralisation as an incentive scheme," Oxford Review of Economic Policy, 3(2), 24-43.

Sole-Olle, A. (2006): "Expenditure spillovers and fiscal interactions: Empirical evidence from local governments in Spain," Journal of Urban Economics, 59(1), 32-53. 
Vives, X. (1999): Olipoly pricing. Old ideas and new tools. The MIT Press, Cambridge, Massachusetts.

Vo, D. H. (2010): "The economics of fiscal decentralization," Journal of Economic Surveys, $24(4), 657-679$. 


\section{A Appendix}

\section{A.1 Figure and Tables}

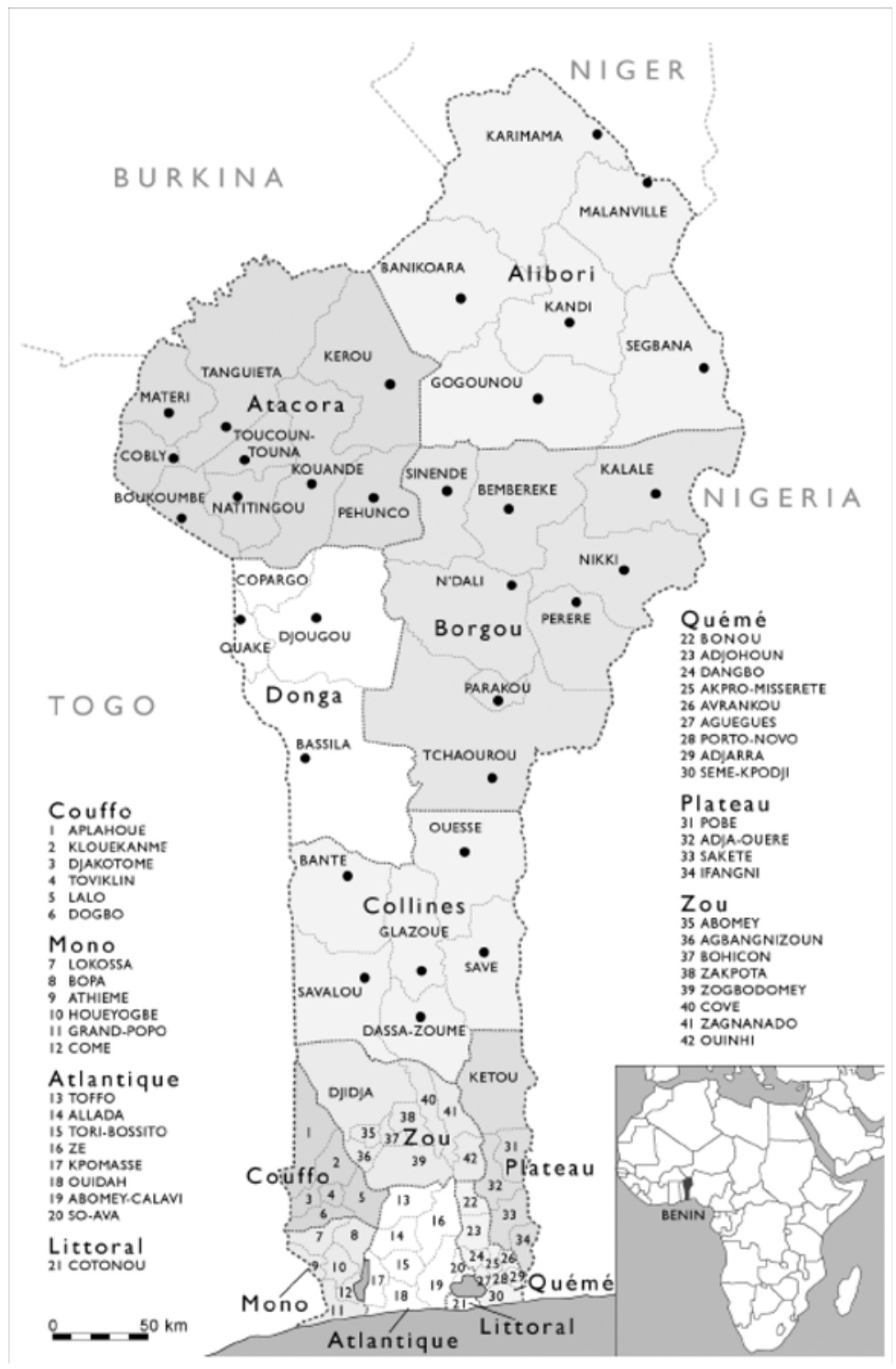

Map 1: Administrative map of Benin 


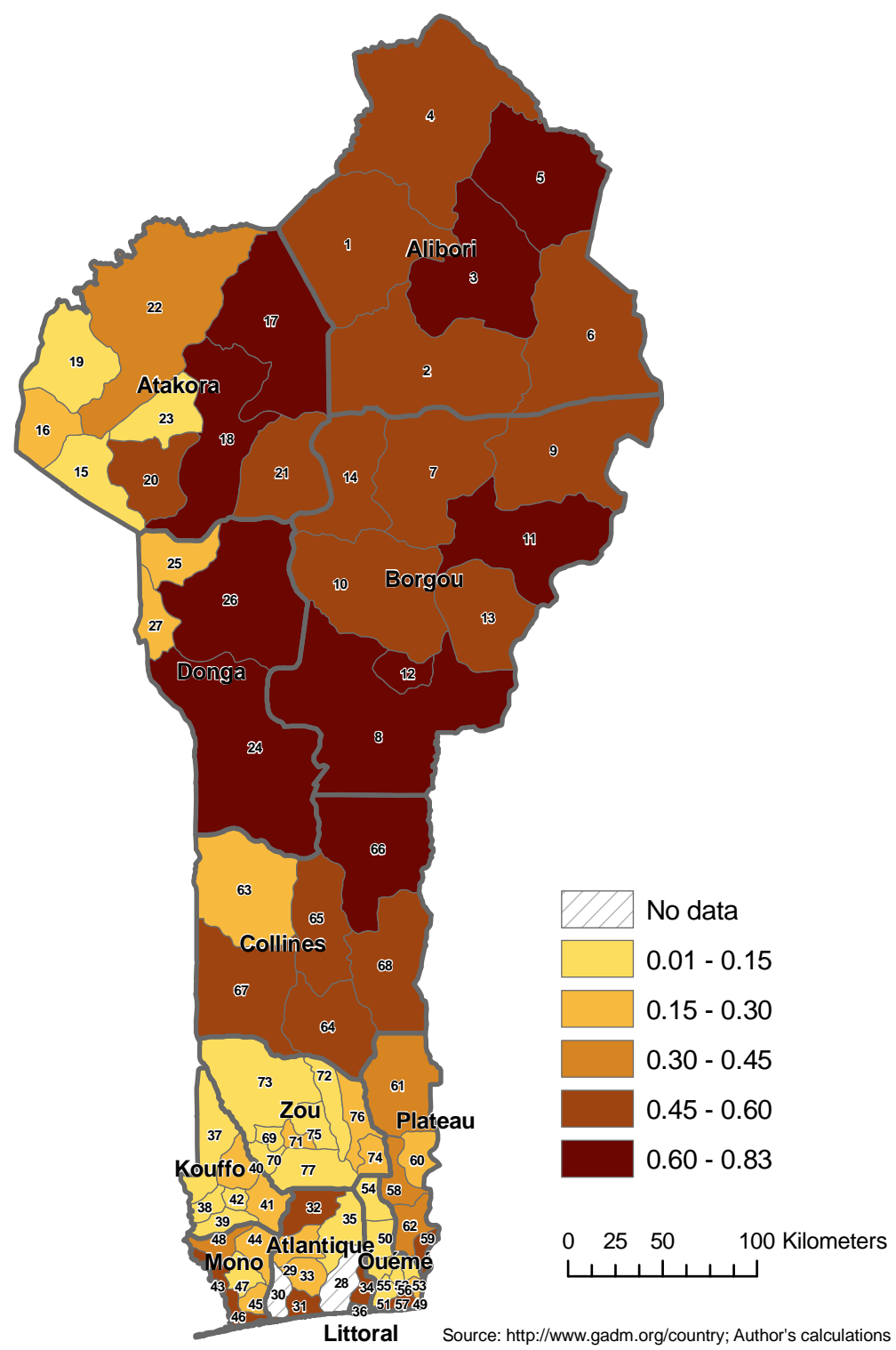

Map 2: Ethnic fragmentation 


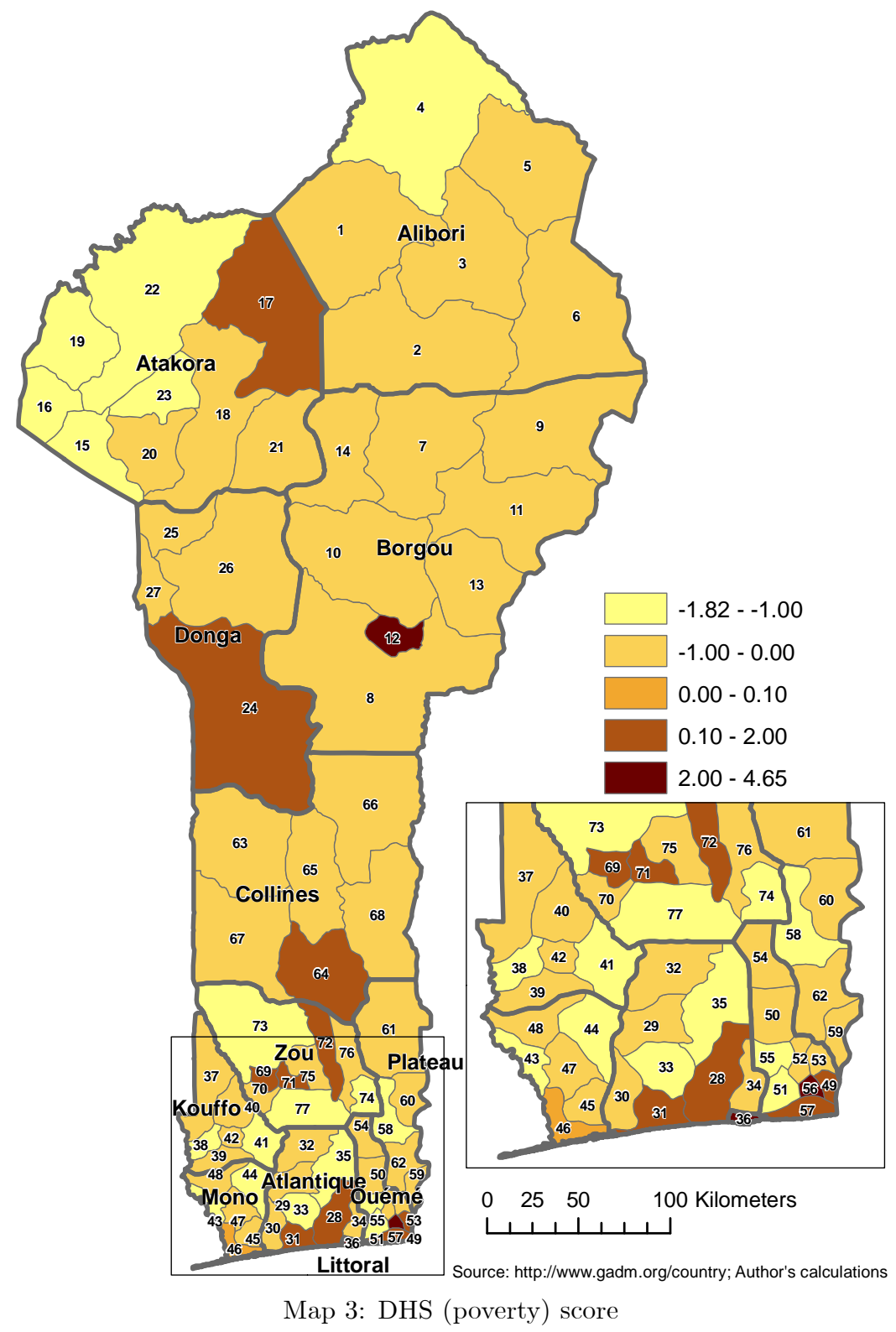


Table 1: Estimation results for the presence of scale economies - Specific effects

Dependent variable: Current expenditure of 'commune' $i\left(G_{i ; t}\right)$

Population density $2.540^{* *}(1.41)$

Squared Population density $\quad 0.001^{* * *}(0.00)$

Haussman test: p-value $\quad 0.34$

Observations $\quad 429$

Robust standard errors are in brackets.***: coefficient significant at 1 percent level, **: at 5 percent level, *: at 10 percent level.

Table 2: LM tests - Spatial lag and spatial error dependence

\begin{tabular}{lllll}
\hline \hline Weighting scheme & $(1) \theta^{\text {neigh }}$ & (2) $\theta^{\text {ethn }}$ \\
\hline LMlag (p-value) & 13.33 & $(0.001)$ & 11.97 & $(0.005)$ \\
LMerr (p-value) & 1.35 & $(0.25)$ & 0.60 & $(0.43)$ \\
Observations & 462 & 462 & \\
\hline \hline
\end{tabular}




\begin{tabular}{lcccc}
\hline \hline Dependent variable: Current expenditure of 'commune' $i\left(G_{i ; t}\right)$ & & & \\
Weighting scheme & $(1) \theta^{\text {neigh }}$ & $(2) \theta^{e t h n}$ & \\
\hline Spending in city $j$ & $0.255^{* * *}(0.07)$ & $0.443^{* *}$ & $(0.19)$ \\
Population density & 0.025 & $(0.06)$ & 0.022 & $(0.06)$ \\
Employment rate & -0.003 & $(0.01)$ & -0.003 & $(0.01)$ \\
Trade openness & $0.115^{* *}$ & $(0.05)$ & $0.167^{* * *}$ & $(0.05)$ \\
Partisan Affiliation & $0.288^{* *}$ & $(0.11)$ & $0.244^{* *}$ & $(0.11)$ \\
Trend & $-0.124^{* *}$ & $(0.05)$ & $-0.065^{* *}$ & $(0.01)$ \\
Election year t-1 & $0.214^{* *}$ & $(0.09)$ & $0.169^{*}$ & $(0.10)$ \\
Election year t & $-0.666^{* * *}(0.19)$ & -0.361 & $(0.30)$ \\
Election year t+1 & $-0.568^{* * *}(0.09)$ & $-0.549^{* * *}$ & $(0.10)$ \\
\hline Log-likelihood & -206.54 & -207.57 & \\
\hline \hline
\end{tabular}

Robust standard errors are in brackets.***: coefficient significant at 1 percent level, **: at 5 percent level, *: at 10 percent level. 
Table 4: Estimation results for dynamic model - GMM-System ${ }^{35}$

\begin{tabular}{|c|c|c|c|c|c|c|c|c|c|c|}
\hline \multicolumn{11}{|c|}{ Dependent variable: Current expenditure of commune $i\left(G_{i ; t}\right)$} \\
\hline Weighting scheme & (1) $\theta^{\text {neigh }}$ & (2) $\theta^{\text {ethn }}$ & (3) $\theta^{\text {uni }}$ & (4) $\theta^{u n i}$ & (5) $\theta^{\text {plac }}$ & (6) $\theta^{e t h n}$ & (7) $\theta^{\text {neigh } 2}$ & (8) $\theta^{\text {ethn2}}$ & (9) $\theta^{\text {neigh }}$ & (10) $\theta^{\text {ethn }}$ \\
\hline \multirow[t]{2}{*}{ Lagged dep. var. } & $0.569^{* * *}$ & $0.527^{* * *}$ & $0.580^{* *}$ & $0.411^{* *}$ & $0.629 * * *$ & $0.403^{* *}$ & $0.410^{*}$ & $0.768^{* * *}$ & $0.678^{* * *}$ & $0.652^{* * *}$ \\
\hline & $(0.22)$ & $(0.21)$ & $(0.22)$ & $(0.20)$ & $(0.21)$ & $(0.19)$ & $(0.27)$ & $(0.14)$ & $(0.21)$ & $(0.21)$ \\
\hline \multirow[t]{2}{*}{ Spending in communes $j$} & $0.623^{* *}$ & $0.513^{* * *}$ & $0.384^{*}$ & $0.472^{* *}$ & -0.202 & $0.468^{* * *}$ & $0.653^{* * *}$ & $0.769 * *$ & 0.155 & 0.130 \\
\hline & $(0.28)$ & $(0.19)$ & $(0.20)$ & $(0.19)$ & $(0.20)$ & $(0.18)$ & $(0.18)$ & $(0.32)$ & $(0.40)$ & $(0.33)$ \\
\hline \multirow[t]{2}{*}{ Population density } & 0.104 & $0.252^{* *}$ & $0.222^{*}$ & 0.179 & 0.173 & $0.210^{*}$ & 0.275 & 0.101 & 0.088 & 0.158 \\
\hline & $(0.11)$ & $(0.11)$ & $(0.12)$ & $(0.12)$ & $(0.10)$ & $(0.12)$ & $(0.12)$ & $(0.08)$ & $(0.11)$ & $(0.10)$ \\
\hline \multirow[t]{2}{*}{ Employment rate } & $0.052^{* * *}$ & $0.020 *$ & $0.011^{*}$ & $0.061^{* * *}$ & 0.015 & $0.060 * * *$ & $0.059^{* * *}$ & $0.037^{* *}$ & $0.032^{* *}$ & $0.017^{*}$ \\
\hline & $(0.02)$ & $(0.01)$ & $(0.008)$ & $(0.01)$ & $(0.01)$ & $(0.01)$ & $(0.01)$ & $(0.01)$ & $(0.01)$ & $(0.01)$ \\
\hline \multirow[t]{2}{*}{ Trade openness } & -0.080 & -0.073 & -0.094 & -0.001 & $-0.148^{* *}$ & -0.025 & -0.054 & -0.106 & $-0.117^{*}$ & $-0.135^{*}$ \\
\hline & $(0.06)$ & $(0.07)$ & $(0.08)$ & $(0.07)$ & $(0.07)$ & $(0.07)$ & $(0.08)$ & $(0.07)$ & $(0.06)$ & $(0.07)$ \\
\hline \multirow[t]{2}{*}{ Partisan Affiliation } & $0.395^{* *}$ & $0.722^{* *}$ & 0.239 & $0.612^{* * *}$ & 0.143 & $0.953^{* * *}$ & $0.528 * *$ & $0.813^{* *}$ & 0.131 & $0.453^{*}$ \\
\hline & $(0.15)$ & $(0.31)$ & $(0.18)$ & $(0.21)$ & $(0.15)$ & $(0.31)$ & $(0.23)$ & $(0.33)$ & $(0.38)$ & $(0.35)$ \\
\hline \multirow[t]{2}{*}{ Trend } & $-0.469^{* * *}$ & $-0.285^{* * *}$ & $-0.297^{* * *}$ & $-0.347^{* * *}$ & $-0.419^{* * *}$ & $-0.345^{* * *}$ & $-0.443^{* * *}$ & $-0.419 * * *$ & $-0.512^{* * *}$ & $-0.463^{*}$ \\
\hline & $(0.11)$ & $(0.09)$ & $(0.10)$ & $(0.11)$ & $(0.05)$ & $(0.10)$ & $(0.09)$ & $(0.06)$ & $(0.11)$ & $(0.09)$ \\
\hline \multirow[t]{2}{*}{ Election year t-1 } & $0.347^{* * *}$ & $0.294^{* *}$ & $0.348^{* *}$ & $0.207^{* *}$ & $0.434^{* * *}$ & $0.190^{*}$ & $0.305^{* * *}$ & $0.343^{* * *}$ & $0.494^{* * *}$ & $0.584^{* * *}$ \\
\hline & $(0.11)$ & $(0.13)$ & $(0.14)$ & $(0.11)$ & $(0.10)$ & $(0.11)$ & $(0.10)$ & $(0.11)$ & $(0.17)$ & $(0.16)$ \\
\hline \multirow[t]{2}{*}{ Election year t } & -0.055 & $-0.482^{* *}$ & $-0.502^{* *}$ & 0.672 & $-1.077^{* * *}$ & -0.244 & -0.215 & -0.241 & -0.044 & -0.112 \\
\hline & $(0.02)$ & $(0.24)$ & $(0.25)$ & $(0.42)$ & $(0.39)$ & $(0.38)$ & $(0.49)$ & $(0.53)$ & $(0.63)$ & $(0.29)$ \\
\hline \multirow[t]{2}{*}{ Election year $t+1$} & $-0.307^{* *}$ & $-0.357^{* * *}$ & $-0.391^{* * *}$ & $-0.090^{*}$ & $-0.569 * * *$ & -0.318 & $-0.318^{* * *}$ & $-0.257^{*}$ & $-0.497^{* *}$ & $-0.567 * * *$ \\
\hline & $(0.12)$ & $(0.09)$ & $(0.09)$ & $(0.11)$ & $(0.10)$ & $(0.10)$ & $(0.11)$ & $(0.14)$ & $(0.19)$ & $(0.11)$ \\
\hline Spending in neighbours & & & & $0.794^{* * *}$ & & $0.617^{* *}$ & & & & \\
\hline$j$ & & & & $(0.20)$ & & $(0.20)$ & & & & \\
\hline \multirow[t]{2}{*}{ Interact term $A F_{i t}$} & & & & & & & & & $0.592^{* *}$ & $0.673^{* *}$ \\
\hline & & & & & & & & & $(0.25)$ & $(0.32)$ \\
\hline \multirow[t]{2}{*}{ Fiscal autonomy } & & & & & & & & & $-4.405^{* *}$ & $-4.784^{*}$ \\
\hline & & & & & & & & & $(1.78)$ & $(2.56)$ \\
\hline AR(1) test: p-value & 0.004 & 0.001 & 0.001 & 0.005 & 0.000 & 0.002 & 0.030 & 0.000 & 0.001 & 0.000 \\
\hline $\mathrm{AR}(2)$ test: $\mathrm{p}$-value & 0.240 & 0.138 & 0.101 & 0.300 & 0.102 & 0.315 & 0.425 & 0.209 & 0.117 & 0.152 \\
\hline Hansen test: p-value & 0.176 & 0.201 & 0.126 & 0.568 & 0.007 & 0.502 & 0.403 & 0.130 & 0.242 & 0.584 \\
\hline $\mathrm{Nb}$ of instruments & 19 & 19 & 19 & 28 & 19 & 28 & 19 & 19 & 25 & 25 \\
\hline $\mathrm{Nb}$ of units & 63 & 63 & 63 & 63 & 63 & 63 & 62 & 62 & 63 & 63 \\
\hline $\mathrm{N}$ & 324 & 324 & 324 & 324 & 324 & 324 & 319 & 318 & 324 & 324 \\
\hline
\end{tabular}

\footnotetext{
${ }^{35}$ Robust standard errors. are in brackets.***: coefficient significant at $1 \%$ level, **: at $5 \%$ level, *: at $10 \%$ level. We adopt the assumption of weak exogeneity of employment rates and trade openness. The weighted average vector of per capita public spending of other local governments is, as noted before, suspected of endogeneity. Other explanatory variables (Population density, time dummies, election dummies, partisan affiliation, trends) are assumed to be strictly exogenous. The lagged levels of variables are used as instruments in the regressions in level as well as in the regressions in difference. We collapse instruments and limit the number. The lags of at least two earlier periods for weak exogenous variables and three earlier periods for endogenous variables are used as instruments. The lagged dependent variable is instrumented by lags of the dependent variable from at least two earlier periods. We use two lags for endogenous and weak exogenous variables.
} 
Table 5: Estimation results for dynamic model 1994-1998 - GMM-System ${ }^{36}$

\begin{tabular}{lllll}
\hline \hline Dependent variable: Current expenditure of commune $i\left(G_{i ; t}\right)$ & & \\
Weighting scheme & $(1) \theta^{\text {neigh }}$ & $(2) \theta^{\text {ethn }}$ & $(3) \theta^{\text {neigh } 2}$ & $(4) \theta^{\text {ethn } 2}$ \\
\hline Lagged dep. var. & $0.835^{* * *}$ & $0.872^{* * *}$ & $0.887^{* * *}$ & $0.965^{* * *}$ \\
& $(0.14)$ & $(0.12)$ & $(0.11)$ & $(0.10)$ \\
Spending in communes $j$ & -0.093 & 0.205 & 0.002 & 0.926 \\
& $(0.13)$ & $(0.25)$ & $(0.35)$ & $(0.85)$ \\
Population density & 0.082 & 0.061 & 0.041 & 0.001 \\
& $(0.05)$ & $(0.04)$ & $(0.02)$ & $(0.05)$ \\
Employment rate & 0.012 & 0.008 & 0.001 & 0.005 \\
& $(0.01)$ & $(0.01)$ & $(0.01)$ & $(0.01)$ \\
Trade openness & -0.001 & -0.001 & -0.001 & -0.006 \\
& $(0.005)$ & $(0.005)$ & $(0.005)$ & $(0.005)$ \\
Partisan Affiliation & 0.095 & 0.225 & 0.022 & 0.001 \\
& $(0.12)$ & $(0.23)$ & $(0.07)$ & $(0.08)$ \\
Trend & -0.001 & -0.038 & -0.001 & -0.168 \\
& $(0.11)$ & $(0.04)$ & $(0.03)$ & $(0.14)$ \\
\hline AR $(1)$ test: p-value & 0.001 & 0.001 & 0.001 & 0.001 \\
AR $(2)$ test: p-value & 0.840 & 0.726 & 0.881 & 0.751 \\
Hansen test: p-value & 0.262 & 0.467 & 0.494 & 0.553 \\
Nb of instruments & 16 & 16 & 16 & 16 \\
Nb of units & 63 & 63 & 62 & 63 \\
N & 241 & 241 & 237 & 241 \\
\hline \hline
\end{tabular}

\footnotetext{
${ }^{36}$ Robust standard errors. are in brackets. ${ }^{* * *}$ : coefficient significant at $1 \%$ level, $* *$ : at $5 \%$ level, *: at $10 \%$ level. We adopt the assumption of weak exogeneity of employment rates and trade openness. The weighted average vector of per capita public spending of other local governments is, as noted before, suspected of endogeneity. Other explanatory variables (Population density, time dummies, election dummies, partisan affiliation, trends) are assumed to be strictly exogenous. The lagged levels of variables are used as instruments in the regressions in level as well as in the regressions in difference. We collapse instruments and limit the number. The lags of at least two earlier periods for weak exogenous variables and three earlier periods for endogenous variables are used as instruments. The lagged dependent variable is instrumented by lags of the dependent variable from at least two earlier periods. We use two lags for endogenous and weak exogenous variables.
} 
Table 6: Testing for yardstick competition - GMM-System ${ }^{37}$

\begin{tabular}{|c|c|c|c|c|}
\hline \multicolumn{5}{|c|}{ "Dependent variable: Current expenditure of 'commune' $i\left(G_{i ; t}\right)$} \\
\hline Weighting scheme & (2) $\theta^{\text {neigh }}$ & (2) $\theta^{\text {ethn }}$ & (3) $\theta^{\text {neigh } 2}$ & (4) $\theta^{\text {ethn } 2}$ \\
\hline \multirow[t]{2}{*}{ Spending in non election years } & $0.915^{* * *}$ & $1.239^{* * *}$ & $0.897^{* * *}$ & $1.013^{* * *}$ \\
\hline & $(0.11)$ & $(0.12)$ & $(0.14)$ & $(0.11)$ \\
\hline \multirow[t]{2}{*}{ Spending in election years } & $0.989^{* * *}$ & $1.289^{* * *}$ & $1.002^{* * *}$ & $1.449^{* * *}$ \\
\hline & $(0.09)$ & $(0.13)$ & $(0.09)$ & $(0.26)$ \\
\hline \multirow[t]{2}{*}{ Lagged dep. var. } & $0.569 * * *$ & $0.434^{* *}$ & $0.695^{* * *}$ & $0.521^{*}$ \\
\hline & $(0.22)$ & $(0.24)$ & $(0.21)$ & $(0.29)$ \\
\hline \multirow[t]{2}{*}{ Population density } & 0.052 & $0.333^{* * *}$ & $0.190^{*}$ & 0.222 \\
\hline & $(0.11)$ & $(0.12)$ & $(0.10)$ & $(0.16)$ \\
\hline \multirow[t]{2}{*}{ Employment rate } & $0.068^{* * *}$ & $0.031^{* *}$ & $0.070^{* * *}$ & $0.068^{* * *}$ \\
\hline & $(0.01)$ & $(0.01)$ & $(0.01)$ & $(0.02)$ \\
\hline \multirow[t]{2}{*}{ Trade openness } & $-0.138^{*}$ & -0.020 & $-0.212^{* * *}$ & -0.016 \\
\hline & $(0.07)$ & $(0.08)$ & $(0.07)$ & $(0.11)$ \\
\hline \multirow[t]{2}{*}{ Partisan Affiliation } & $0.476^{* *}$ & $1.510^{* * *}$ & $0.507^{* *}$ & $1.462^{* * *}$ \\
\hline & $(0.24)$ & $(0.28)$ & $(0.22)$ & $(0.36)$ \\
\hline \multirow[t]{2}{*}{ Trend } & $-0.430^{* * *}$ & -0.097 & $-0.482^{* * *}$ & $-0.365^{* * *}$ \\
\hline & $(0.08)$ & $(0.08)$ & $(0.07)$ & $(0.12)$ \\
\hline \multirow[t]{2}{*}{ Election years } & -0.387 & 0.353 & -0.570 & $3.577^{*}$ \\
\hline & $(0.40)$ & $(0.76)$ & $(0.72)$ & $(2.17)$ \\
\hline $\mathrm{AR}(1)$ test: $\mathrm{p}$-value & 0.003 & 0.001 & 0.001 & 0.201 \\
\hline $\mathrm{AR}(2)$ test: $\mathrm{p}$-value & 0.193 & 0.186 & 0.517 & 0.106 \\
\hline Hansen test: p-value & 0.153 & 0.123 & 0.492 & 0.125 \\
\hline Wald test: p-value & 0.157 & 0.438 & 0.264 & 0.112 \\
\hline $\mathrm{Nb}$ of instruments & 20 & 20 & 20 & 20 \\
\hline $\mathrm{Nb}$ of units & 62 & 63 & 62 & 62 \\
\hline $\mathrm{N}$ & 324 & 324 & 319 & 318 \\
\hline
\end{tabular}

\footnotetext{
${ }^{37}$ Robust standard errors. are in brackets.***: coefficient significant at $1 \%$ level, ${ }^{* *}$ : at $5 \%$ level, *: at $10 \%$ level. We adopt the assumption of weak exogeneity of employment rates and trade openness. The weighted average vector of per capita public spending of other local governments is, as noted before, suspected of endogeneity. Other explanatory variables (Population density, time dummies, election dummies, partisan affiliation, trends) are assumed to be strictly exogenous. The lagged levels of variables are used as instruments in the regressions in level as well as in the regressions in difference. We collapse instruments and limit the number. The lags of at least two earlier periods for weak exogenous variables and three earlier periods for endogenous variables are used as instruments. The lagged dependent variable is instrumented by lags of the dependent variable from at least two earlier periods. We use two lags for endogenous and weak exogenous variables.
} 